\title{
BMJ Open Factors associated with HIV in younger and older adult men in South Africa: findings from a cross-sectional survey
}

Kaymarlin Govender, ${ }^{1}$ Sean Edward Beckett (D) ${ }^{1}$ Gavin George, ${ }^{1}$ Lara Lewis, ${ }^{2}$
Cherie Cawood, ${ }^{3}$ David Khanyile, ${ }^{3}$ Frank Tanser, ${ }^{2,4,5,6}$ Ayesha BM Kharsany ${ }^{2}$

To cite: Govender K, Beckett SE, George G, et al. Factors associated with HIV in younger and older adult men in South Africa: findings from a crosssectional survey. BMJ Open 2019;9:e031667. doi:10.1136/ bmjopen-2019-031667

- Prepublication history and additional material for this paper are available online. To view these files, please visit the journal online (http://dx.doi. org/10.1136/bmjopen-2019031667).

Received 16 May 2019

Revised 26 November 2019

Accepted 27 November 2019

Check for updates

(c) Author(s) (or their employer(s)) 2019. Re-use permitted under CC BY-NC. No commercial re-use. See rights and permissions. Published by BMJ.

${ }^{1}$ HEARD, University of KwaZulu Natal, Durban, KwaZulu-Natal, South Africa

${ }^{2}$ Centre for the AIDS Programme of Research in South Africa (CAPRISA), University of KwaZulu-Natal, Durban, KwaZulu-Natal, South Africa

${ }^{3}$ Epicentre AIDs Risk

Management, Cape Town,

Western Cape, South Africa

${ }^{4}$ Lincoln Institute for Health,

University of Lincoln, Lincoln,

United Kingdom

${ }^{5}$ Africa Health Research Institute, Durban, KwaZulu-Natal, South Africa

${ }^{6}$ School of Nursing and Public Health, University of KwaZuluNatal, Durban, South Africa

Correspondence to

Sean Edward Beckett;

Becketts@ukzn.ac.za

\section{ABSTRACT}

Objective This study investigated the behavioural, psychosocial and biological factors associated with HIV in a younger group of men (15 to 24 years) compared with an older group of men ( 25 to 35 years).

Design A household-based, cross-sectional study was conducted.

Setting Men were randomly selected using a two-stage random sampling method in KwaZulu-Natal, South Africa, between June 2014 and June 2015.

Participants Overall, we interviewed 1472 younger men and 1138 older men. Only participants who could speak English or Zulu, were able to provide informed consent and who were expected to be living in the study area for the next 12 months were enrolled into the study.

Primary and secondary outcomes HIV status was the primary outcome for the study. Men's HIV status was derived from blood samples collected in the study which were tested for HIV antibodies.

Results HIV prevalence was higher among older men (35.4\%, 95\% Cl: 31.7 to 39.1$)$ than younger men $(7.6 \%$, $95 \% \mathrm{Cl}: 6.2$ to $9.4, \mathrm{p}<0.01)$. Older men, who completed secondary school had a lower likelihood of being HIV positive (adjusted OR (AOR): $0.41,95 \% \mathrm{Cl}: 0.27$ to 0.63 , $\mathrm{p}<0.001$ ) and those with greater food insecurity had a higher likelihood of being HIV positive (AOR: $1.57,95 \% \mathrm{Cl}$ : 1.05 to $2.34, p=0.04)$. Younger men with a higher number of lifetime sexual partners had a higher likelihood of being HIV positive (AOR: $1.04,95 \%$ Cl: 0.99 to $1.09, \mathrm{p}=0.09$ ). Conclusion Given that the HIV prevalence is higher in the older men, community based interventions need to target older men for medical circumcision and support HIV positive men to improve their material conditions early. For younger men intervening to reduce HIV risk behaviours at a young age before these behaviours become entrenched should be central to HIV prevention programmes.

\section{BACKGROUND}

According to Joint United Nations Programme on HIV/AIDS (UNAIDS) estimates for 2018, South Africa has 2.8 million men aged 15 years or older living with HIV. ${ }^{1}$ Comparatively this number is significantly higher than HIV prevalence rates in other countries in the Eastern and Southern African region. Men who are HIV positive are underrepresented in HIV testing, treatment and care in South

\section{Strengths and limitations of this study}

The study was able to access a large sample of vulnerable men in one of the highest HIV burden districts in South Africa.

- The study collected data on a number of psychosocial measures and sexual behaviour measures in a real-world setting.

- Respondent's HIV status was taken from blood samples and is therefore not susceptible to self-report bias.

- The study is geographically limited.

- The study collected data on a number of psychosocial measures and sexual behaviour measures in a real-world setting.

Africa. ${ }^{2}$ Men are less likely to know their HIV status when compared with women. Proportionately fewer men and boys benefit from HIV treatment and care programmes than women and girls, and the health outcomes for men with HIV are poorer. ${ }^{3}$ Men have received considerably less attention in terms of understanding the psychosocial and structural factors influencing their ability to access HIV prevention and treatment programmes. ${ }^{4}$ Not surprisingly, men are less likely than women to undergo HIV testing and more likely to start antiretroviral therapy (ART) at advanced disease stages and interrupt or drop out of ART. ${ }^{5}$

While HIV prevalence from a nationally representative household survey among South African men, from 15 to 49 years of age in 2017 was approximately $14.8 \%$, disaggregation by age shows that prevalence is $4.7 \%$ among men 15 to 19 years old, $4.8 \%$ among men 20 to 24 years old, $12.4 \%$ among men 25 to 29 years old and $18.4 \%$ among men 30 to 35 years old. ${ }^{6}{ }^{1}$ Although HIV incidence has receded for men from a high of 210000 new infections in the year 1998 to 86000 new infections in the year 2018, infections rates in South Africa remain the highest in 
the region, according to UNAIDS modelled data. ${ }^{1}$ Over time, incidence rates obtained from nationally representative household surveys appears to have remained stable among young South African men (15 to 24 years) at $0.6 \%$ in $2005,1.0 \%$ in 2012 and $0.7 \%$ in $2017 .^{6-8}$ Incidence data, based on a demographic surveillance area in rural KwaZulu-Natal, indicates that HIV incidence amongst men starts rising rapidly with the onset of adulthood (from the age of 18 and peaks at age 30 ), ${ }^{9}$ with incidence rates peaking much later for men than for women. ${ }^{8}$ More generally, high levels of HIV incidence in men have been attributed to multiple sexual partners, transactional sex, age disparate sexual partnerships, inconsistent condom use and alcohol abuse that are manifested in norms which emphasise male power within sexual relationships. ${ }^{10-15}$

While there is some evidence characterising HIV risk behaviours amongst men across different age categories, ${ }^{8}$ data remains sparse. In a national survey, conducted in 2012, rates of multiple sexual partners (two or more partners in a year) were higher in 15- to 24-year-old men than the 25 - to 49 -year-old men (37.5\% vs $18.3 \%$, respectively). Condom use at last sex was higher for men aged 15 to 24 years of age $(68 \%)$ than men aged 25 to 49 years of age $(36 \%)$. In addition, older men are more likely to engage in sex with a younger female partner ${ }^{16}$ and these age disparate relationships are associated with a higher likelihood of HIV acquisition in younger women and in older men (25 to 35 years old: $53.6 \%$ vs 36 to 55 years old: $35.0 \%$, respectively). ${ }^{1718}$ The take-up of voluntary medical male circumcision (VMMC) also differs according to age, as older men are less likely to take-up VMMC than younger men (25 to 49 years: $39 \%$ medically circumcised vs 15 to 24 years: $52 \%$ medically circumcised) ${ }^{8}$ The nationally representative survey data appears to highlight increased risk behaviours amongst younger men with regards to number of partners and condom use although younger men are more likely to be circumcised. That older men appear to be more likely to engage in age disparate partnership is a key risk behaviour for this group. The inconsistent findings presented above need to be investigated in more depth to understand why HIV incidence increases so rapidly for older men yet they appear to engage in less risky behaviour than younger men.

The inconsistencies in the comparative data especially on behavioural factors associated with HIV further hampers our understanding of how to tailor HIV messaging for these two population of men (young men and older men). Given that the epidemic in South Africa is largely a heterosexual one, this paper therefore sought to compare two populations of heterosexual men at different inflection points in the HIV epidemic in a very high HIV prevalence district in KwaZulu-Natal in South Africa. More specifically, we compared HIV prevalence and HIV related risk factors for men aged 15 to 24 years of age (young men) and 25 to 35 years of age (older men). We focus on these two adjacent age ranges because of the disjuncture in transitions from low to high HIV acquisition. In addition to biological markers, this paper uses socio-demographic, economic, psychological and social measures to enable a comprehensive analysis of men in these two age bands. The latter measures include perceived risk for contracting HIV, gender inequitable norms, HIV-related stigma and depressive symptoms to profile the men in this study.

\section{METHODS}

\section{Study population and setting}

The data from this study originate from the HIV Incidence Provincial Surveillance System, which was established in rural Vulindlela and the adjoining peri-urban Greater Edendale areas in the uMgungundlovu district of KwaZulu-Natal, South Africa. The surveillance system was established in 2014 with data collection stopped in 2015. The location and design of the study have been described in detail elsewhere. ${ }^{19}$ Approximately 360000 individuals live in this area (48\% male and $52 \%$ female) and reside in approximately 96000 households. The area is characterised by high levels of poverty and poor infrastructure. The Greater Edendale area is the economic hub of the uMgungundlovu district. The Greater Edendale area consists of both formal and informal housing, as well as ancillary land use. More than a quarter (28\%) of men aged 15 to 49 years are HIV positive in this community. ${ }^{20}$ HIPSS was setup to provide data on HIV prevalence and incidence and to assess whether HIV prevention and treatment efforts are impacting on HIV incidence at a population level.

\section{Sample}

A multistage cluster sampling design was used to select study participants within enumeration areas (EA) and households as primary and secondary sampling units, respectively. An EA is a physical geographic area covered by one fieldworker during the census and is the smallest geographical area into which the country is divided. EAs were randomly selected from a sampling frame constructed from Statistics South Africa's 2011 census, the 2007 Community Survey and aerial imaging of dwellings supplied by the 2011-midyear estimates of GeoTerra imaging. Different sources were used to determine the number of households in an EA. The number of houses in an EA change as new houses are built and old ones are destroyed. The different data sources were used to triangulate the data and to be certain on the composition of each EA. Within the EA, households were systematically selected from a random starting point. A household roster was completed and one household member aged 15 to 49 years was randomly selected and invited to complete the individual level questionnaire. However, this paper focuses specifically on two populations of men: 15 to 24 years $(n=1472)$ and 25 to 35 years $(n=1138)$. We used the cut-off at the age of 24 years as this is where HIV prevalence starts to increase dramatically for men. ${ }^{6}$ We only analysed men up to the age of 35 years as young men 
are less likely to take-up HIV prevention and treatment activities.

\section{Patient and public involvement}

The research tools and outcome measures were developed after conducting a literature review on the factors that impact HIV infection in South Africa. Patients were not involved in the study design. Patients were not directly involved in the recruitment and conduct of the study although a community advisory board was used to make sure the community had input into the study. The results of HIV tests were sent to local clinics and a barcode was given to each patient for them to collect their results, additionally, patients were offered a rapid HIV test after the survey.

\section{Data}

Data collection took place from June 2014 to June 2015 by means of a structured questionnaire administered on a personal digital assistant. Interviews were conducted in either English or Zulu. A head of the household was selected to complete a household questionnaire which elicited the number of individuals living in the household and a number of other socio-demographic and economic indicators on household members. The individual level questionnaire elicited the age of respondent, whether the respondent had completed secondary schooling, marital status of the respondent and whether respondents had spent more than 1 month away from home in the previous 12 months. In addition, we assessed knowledge of preventing HIV, depressive symptoms (Centre for Epidemiological Studies Depression scale), ${ }^{21}$ perceptions of risk for contracting HIV, gender inequitable attitudes (Gender Equitable Men's scale) and HIV-related stigma (see online supplementary appendix 1 for more detail on items and scales). Self-reported behaviours assessed included age at first sex, condom use at first sex and in the previous 12 months, number of partners in the previous 12 months and in their lifetime, exchange of money and goods for sex (transactional sex), age of sexual partners, length of sexual relationship, number of sexual acts with most recent partner in the previous 12 months and information on each respondents three most recent sexual partners. The following self-reported behaviours were also included, uptake of HIV testing services, alcohol use, access and uptakeof HIV prevention information a. HIV status, antiretroviral (ARV) presence, viral suppression and male circumcision (self-reported by the men) the only biological markers used in this paper. Venous blood samples collected by the survey team in the study were tested for HIV antibodies and antigens with fourth generation HIV enzyme immunoassays with the bioMérieux Vironostika Uniform II Antigen/Antibody Microelisa system (bioMérieux, Marcy-l'Étoile, France) and HIV 1/2 Combi Roche Elecsys (Roche Diagnostics, Penzberg, Germany). Positive samples were verified with an HIV-1 western blot assay (Bio-Rad Laboratories, Redmond, Washington, USA) ${ }^{19}$ Study participants provided written informed consent prior to study enrolment, questionnaire administration and clinical sample collection for laboratory measurements. The main member of the household completing the household composition form received a gift valued at approximately 1 US\$. Enrolled participants received a gift to the approximate value of 3 US\$ to compensate for their time. All study participants were offered a HIV rapid test after the interview if they wanted to know their HIV status.

\section{Ethics approval and consent to participate}

Prior to the study extensive community engagement with all stakeholders including health service providers and traditional leaders was undertaken. Written informed consent and assent was sought from study participants. Parental consent and child participant assent was provided for individuals younger than 18 years old.

\section{Statistical analysis}

The final sample was weighted to be representative of the population of the Greater Edendale and Vulindlela areas. All analyses were conducted with SPSS V.23. ${ }^{22}$ Descriptive statistics for the biological, socio-demographic factors, perceptual and behavioural factors for men aged 15 to 24 years and men aged 25 to 35 years were computed. Bivariate relationships, by means of unadjusted ORs (UORs) and $95 \%$ CI for the UOR, of factors associated with HIV status for both populations of men. Separate multivariable logistic regression analyses assessed potential predictors of HIV status for younger and older men. Adjusted ORs (AORs) are presented from the multivariable models. The multivariable models were restricted to only include men who reported being sexually active to potentially remove vertical infections from the sample. ${ }^{23}$ Statistically significant factors from the bivariate analysis and predetermined theoretically significant factors were included in separate age models. We had to remove some variables from the younger age group regression analysis so the regression model would not be overfitted, although the exclusion of these variables had no impact on the overall results. To address life course development confounding in the analysis we included age of the individuals and other socio-demographic factors such as schooling in the regression models. SEs accounted for the complex survey design. A test was considered statistically significant when $\mathrm{p}<0.05$.

\section{RESULTS}

\section{Descriptive statistics}

Overall 2144 households refused participation and 577 individuals refused participation. The full study response rate was $86.9 \%$ (9812 people agreed to participate from 11289 enrolled households). Although we only focused on 2610 men aged 15 to 35 years old from the full sample. Figure 1 highlights the steady increase in HIV prevalence among men in the older age categories. Only $3.6 \%$ of men in the 15- to 16-year-old category were HIV positive, 


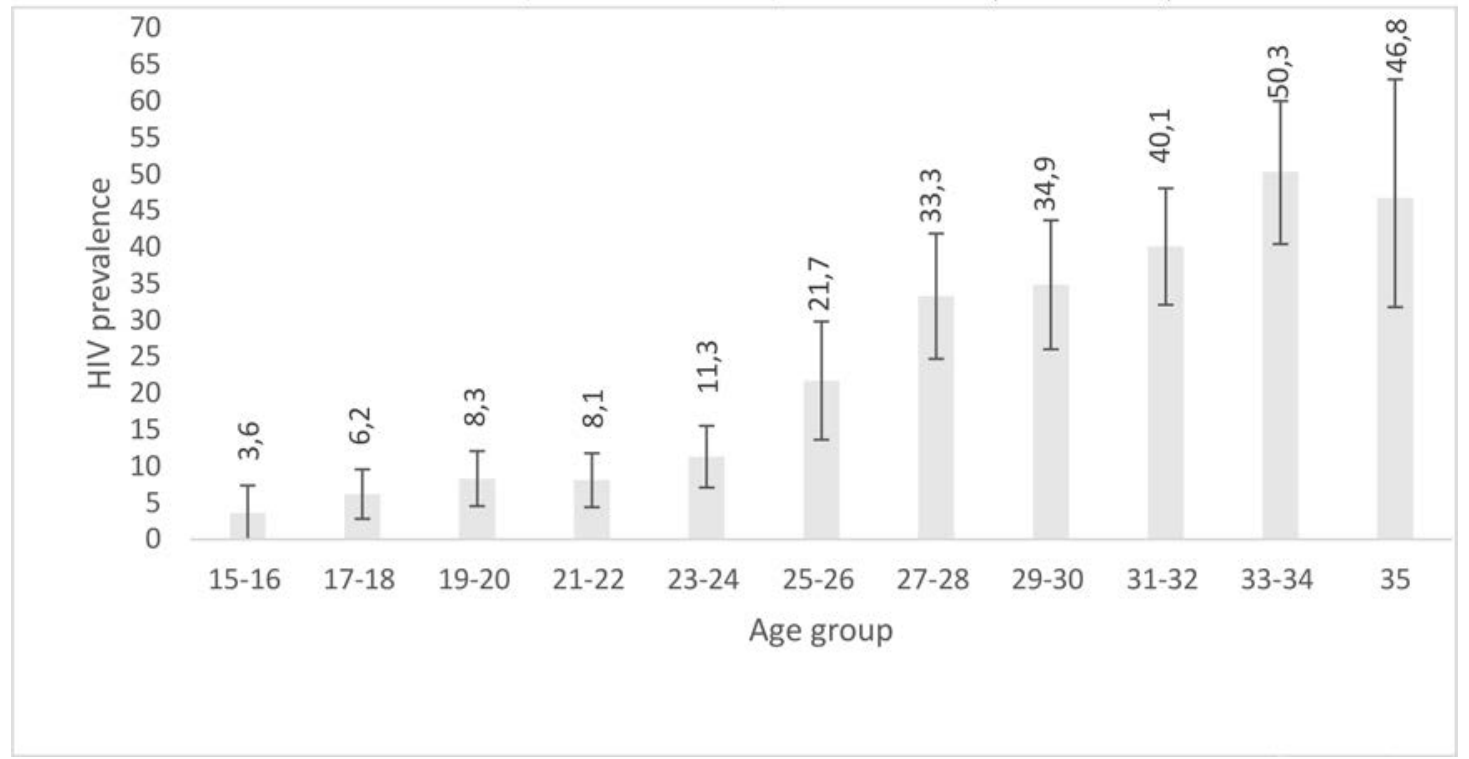

Figure 1 Weighted HIV prevalence by age group (95\% Cls included) in Greater Edendale and Vulindlela areas, KwaZulu-Natal, South Africa (2014 to 2015).

whereas more than half $(50.3 \%)$ of men in the 33 to 34 years old age group were HIV positive. The proportion of HIV positive men who knew their HIV status was the following: 15 to 19 years old: 32\%; 20 to 24 years old: 26\%; 20 to 24 years old: $33 \%$; 25 to 29 years old: $50 \%$ and 30 to 34 years old: $61 \% .{ }^{24} \mathrm{HIV}$ prevalence increases considerably from $21.7 \%$ in the age group 25 to 26 years to $46.8 \%$ in the 35 year age group (figure 1 ). Based on data in figure 1, we created two groups of men according to their age, the first group consists of men aged from 15 to 24 years old (called younger men henceforth) and the second group consists of men aged from 25 to 35 years old (called older men henceforth) to enable modelling of factors associated with HIV prevalence. HIV prevalence was $7.6 \%$ and $35.4 \%$ for the younger men and older men, respectively. Less than one-fifth $(16.6 \%)$ of all HIV positive younger men indicated they were on ARV drugs and just over one-quarter $(26.2 \%)$ of all HIV positive older men indicated they were on ARVs (see table 1). Nearly half $(48.1 \%)$ of the younger men were medically circumcised and just over a quarter $(26.2 \%)$ of the older men were medically circumcised.

The vast majority of men in both populations were single and have never cohabited $(98.4 \%$ and $92.4 \%$, respectively). Just over a third $(36.8 \%)$ of younger men had completed secondary schooling and less than half of the older men $(45.3 \%)$ had completed secondary schooling. However, this may not be accurate for younger men because many of them were younger than the age at which South Africans are expected to have completed secondary school. The minority of younger men and older men were away from home for more than a month in the previous year $(8.4 \%$ and $12.7 \%$, respectively).

With regard to the behavioural factors, there was very low rates of consistent condom use in the previous 12 months among younger men and older men (consistent use: $36.2 \%$ and $20.5 \%$, respectively). Only a minority $(5.0 \%)$ of younger men were engaged in age disparate ( 5 to 9 years older than their female partner) sexual relationships, whereas nearly a third $(29.4 \%)$ of older men engaged in these types of relationships. Younger men had a median of three sexual partners over their lifetime and older men had a median of four sexual partnerships over their lifetime. A minority $(6.8 \%)$ of younger men engaged in transactional sex in the previous 12 months and $13.2 \%$ of older men engaged in transactional sex in the previous 12 months. Approximately a quarter (25.1\%) of younger men perceive themselves as at risk for contracting HIV, comparatively just less than half (42.0\%) of older men perceive themselves at risk of contracting HIV. A minority (12.1\%) of younger men presented with depressive symptoms and $17.1 \%$ of older men reported depressive symptoms.

\section{Bivariate associations with HIV prevalence}

Bivariate analysis are presented for the following variables (socio-demographic, psychological, biological risk and behavioural risk) associated with HIV prevalence in table 2. For younger men, factors associated with HIV included perceiving themselves at risk of contracting HIV (OR: 2.6, 95\% CI: 1.4 to 5.1, p<0.01). However, being medically circumcised was associated with lower odds of HIV in younger men (OR: $0.5,95 \%$ CI: 0.2 to $0.9, \mathrm{p}=0.02)$. Factors related to HIV status for older men include, not having completed schooling (OR: 2.2, $95 \%$ CI: 1.5 to $3.0, \mathrm{p}<0.01$ ), being food secure (OR: 0.5 , $95 \%$ CI: 0.4 to $0.8, \mathrm{p}<0.01)$, being medically circumcised (OR: $0.4,95 \%$ CI: 0.3 to $0.7, \mathrm{p}<0.01$ ), and perceiving oneself at risk for contracting HIV (OR: 1.8, 95\% CI: 1.2 to $1.7, \mathrm{p}<0.01)$. 
Table 1 Biological, socio-demographic, behavioural and psychosocial factors for men aged 15 to 24 years old and men aged 25 to 35 years old in greater Edendale and Vulindlela areas, KwaZulu-Natal, South Africa (2014 to 2015)*

\begin{tabular}{|c|c|c|c|c|}
\hline & \multicolumn{2}{|c|}{$15-24$ year olds $(n=1472)$} & \multicolumn{2}{|c|}{$25-35$ year olds $(n=1138)$} \\
\hline & $\begin{array}{l}\text { Weighted \%/ } \\
\text { median }\end{array}$ & $\begin{array}{l}\text { Unweighted } \\
\mathrm{N}\end{array}$ & $\begin{array}{l}\text { Weighted \%/ } \\
\text { median }\end{array}$ & $\begin{array}{l}\text { Unweighted } \\
\mathrm{N}\end{array}$ \\
\hline \multicolumn{5}{|l|}{ Biological factors } \\
\hline HIV positive (\%) & 7.6 & 123 & 35.4 & 425 \\
\hline Currently on ARVs (self-report) (\%)† & 16.6 & 19 & 26.2 & 101 \\
\hline Virally suppressed (<1000 copies/ml)(\%) & 31.0 & 34 & 31.7 & 129 \\
\hline Who are medically circumcised (\%) & 48.1 & 664 & 26.2 & 296 \\
\hline \multicolumn{5}{|l|}{ Socio-demographic factors } \\
\hline Married (\%) & 0.3 & 3 & 2.3 & 21 \\
\hline Cohabiting (\%) & 1.0 & 12 & 3.3 & 51 \\
\hline Single, never cohabited (\%) & 98.4 & 1453 & 92.4 & 1046 \\
\hline Who have not completed schooling (\%) & 57.0 & 790 & 48.5 & 516 \\
\hline Who have completed secondary schooling (\%) & 36.8 & 578 & 45.3 & 547 \\
\hline Who have completed tertiary schooling (\%) & 6.2 & 102 & 6.2 & 75 \\
\hline Households that does not receive social support grant (\%) & 35.4 & 729 & 42.7 & 687 \\
\hline Household is food insecure (\%) & 22.5 & 259 & 22.0 & 210 \\
\hline Away from home $>1$ month in a year (\%) & 8.4 & 144 & 12.7 & 140 \\
\hline Who have always lived in the community (\%) & 82.4 & 1231 & 82.8 & 917 \\
\hline \multicolumn{5}{|l|}{ Behavioural factors } \\
\hline Who have had sex (\%) & 63.3 & 934 & 92.0 & 1044 \\
\hline Condom used at first sex (\%) & 38.9 & 332 & 14.1 & 142 \\
\hline Consistent condom use for last 12 months (\%) & 36.2 & 260 & 20.5 & 179 \\
\hline 5 to 9 years older than previous partner (\%) & 5.0 & 42 & 29.4 & 284 \\
\hline$>9$ years older than previous partner (\%) & 0.0 & 0 & 4.6 & 41 \\
\hline Engaged in transactional sex (\%) & 6.8 & 121 & 13.2 & 189 \\
\hline$\geq 15$ years old at sex debut (\%) & 14.3 & 93 & 9.6 & 64 \\
\hline No. of sex partners over lifetime (median, range) $\ddagger$ & $3(1-48)$ & 821 & $4(1-113)$ & 870 \\
\hline No. sex partners in previous 12 months. (median, range) $\ddagger$ & $1(0-16)$ & 713 & $1(0-26)$ & 809 \\
\hline Who ever tested for HIV (self-report) (\%) & 67.3 & 924 & 66.4 & 744 \\
\hline Who ever drink alcohol (\%) & 30.3 & 454 & 47.7 & 547 \\
\hline Who attended an HIV community meeting (\%) & 2.7 & 54 & 3.8 & 42 \\
\hline Who watched an HIV play/event (\%) & 13.7 & 192 & 12.8 & 132 \\
\hline Cared for a person who is sick with AIDS (\%) & 1.3 & 26 & 1.6 & 17 \\
\hline $\begin{array}{l}\text { Received HIV info from billboard, newspaper and television } \\
\text { (median, range) }\end{array}$ & $2.0(0-3)$ & 1472 & $2.0(0-3)$ & 1138 \\
\hline \multicolumn{5}{|l|}{ Psychosocial factors } \\
\hline Definitely/probably going to be infected (\%)§ & 25.1 & 352 & 42.0 & 376 \\
\hline Who present with depressive symptoms (\%)§ & 11.9 & 133 & 17.1 & 190 \\
\hline HIV prevention knowledge score (median, range)§ & $3.0(0-8)$ & 1472 & $4.0(0-8)$ & 1138 \\
\hline Gender equitable norms scale score (median, range)§ & $8.0(4-12)$ & 1472 & $8.0(4-12)$ & 1138 \\
\hline Agree PLHIV should be ashamed (\%) & 2.0 & 23 & 2.1 & 21 \\
\hline Agree PLHIV must have done something wrong (\%) & 8.3 & 99 & 4.9 & 46 \\
\hline Agree I don’t want to be friends with PLHIV (\%) & 9.6 & 148 & 7.0 & 96 \\
\hline
\end{tabular}

Continued 


\begin{tabular}{|c|c|c|}
\hline 15-24 year ol & $s(n=1472)$ & $25-35$ year olds $(n=1138)$ \\
\hline $\begin{array}{l}\text { Weighted \%/ } \\
\text { median }\end{array}$ & $\begin{array}{l}\text { Unweighted } \\
\mathrm{N}\end{array}$ & $\begin{array}{l}\text { Weighted \%/ Unweighted } \\
\text { median }\end{array}$ \\
\hline
\end{tabular}

${ }^{*}$ Column proportions and medians are weighted.

†This includes all HIV positive individuals, irrespective of whether they were aware of their HIV status. $\ddagger$ This includes transactional, commercial sex worker, casual and marital partners.

$\S$ See online supplementary appendix 1 for more details on the items in each scale variable.

ARVs, antiretrovirals; PLHIV, people living with HIV.

\section{Multivariate factors associated with HIV status}

Table 3 presents findings from the regression analyses conducted for younger and older men. Younger men who reported higher number of lifetime sexual partners had higher adjusted odds of being HIV positive (AOR: $1.04,95 \%$ CI: 0.99 to $1.09, \mathrm{p}=0.09$ ), although the alpha value was above the five per cent level. Older men who had completed secondary schooling had lower adjusted odds of being HIV positive (AOR: $0.41,95 \%$ CI: 0.27 to $0.63, \mathrm{p}<0.01$ ), older men with food insecurity had higher adjusted odds of being HIV positive (AOR: 1.57, 95\% CI: 1.05 to $2.34, \mathrm{p}=0.04$ ), medically circumcised older men had lower adjusted odds of being HIV positive (AOR: $0.58,95 \%$ CI: 0.35 to $0.97, \mathrm{p}=0.04$ ) and older men who were younger than their most recent sexual partner had higher adjusted odds of being HIV positive (AOR: 3.61, 95\% CI: 1.25 to $10.45, \mathrm{p}=0.02)$.

\section{DISCUSSION}

Our study undertaken in 2014, in rural and peri-urban areas of KwaZulu-Natal, South Africa, shows that HIV prevalence rises sharply among men from the age of 24 years with older men being almost five times more likely to be HIV positive than younger men. Our findings are consistent with research elsewhere, ${ }^{6925}$ with the older group of men being almost five times more likely to be HIV positive than the younger men. ${ }^{10}$ The disparity in prevalence between the two populations of men are consistent with South African national data. ${ }^{6}$ Although men in subSaharan Africa have lower prevalence of HIV, they tend to have poorer clinical outcomes than women. ${ }^{3}$ This situation is reflected in mortality statistics where there has been a faster decline in the mortality rate among women than men since the rapid scale-up of ART. ${ }^{5}$

Our findings add to the literature on HIV prevalence among men in a number of ways. In previous studies, men reported engaging in risky sexual behaviours previously associated with HIV acquisition. ${ }^{10}{ }^{23}$ We found that low proportions of older men reported condom use at first sex and low levels of consistent condom use in the last 12 months. Higher proportions of older men reported engaging in transactional sex and having a higher number of sexual partners in the previous 12 months.

A central point of emphasis in this paper is the need to get men into HIV risk reduction programmes before or as they transition into adulthood. The high levels of these risk behaviours in this older subpopulation could be reflective of the lack of social and behavioural education during their school years and the period post schooling (before they turned 25 years). Scale-up of community based HIV programming only occurred after 2008 and comprehensive sexuality education in schools was initiated in 2013 with rapid scale up between 2013 to $2015 .{ }^{26}$ Social vulnerability issues, such as food security in the household and educational attainment, related to HIV positive status were also prevalent in this group of older men (see table 2 and table 3). These findings could be indicative of a larger proportion of eolder men, compared with younger men, who were probably living with HIV for a longer period and faced multiple issues which result in poor health, such as incomplete education, food insecurity and poorer access to social grants (see table 2). ${ }^{27}$ These findings are also reflective of the high levels of unemployment among working aged men in KwaZulu-Natal province. ${ }^{28}$ HIV programmes should work to ensure treatment adherence among these men coupled with community interventions to support their livelihoods.

Younger men were more likely to have sexually debuted before the age of 15 years, reflecting current trends of early sexual activity. ${ }^{8}$ In comparison to older men, the HIV risk associated with early sexual debut in younger men may have been offset by protective behaviours such as higher levels of condom usage ${ }^{29}$ higher prevalence of male circumcision $^{30}$ and fewer sexual partners over their lifetime in relation to older men. While only $36 \%$ completed secondary schooling, this group would have also benefited from various HIV programmes targeting young people (eg,VMMC programmes, DREAMS male partner programmes). The study findings provide some guidance for HIV prevention programmes. The transition of HIV risk from youth to adulthood means that programmes should target men during adolescence (early in the life cycle) before sexual risk behaviours develop and become entrenched. Male circumcision programmes targeting young men are seen as a viable entry point for introducing related sexual health services. ${ }^{30}$ In addition, study results suggest that more emphasis should be placed on the lost generation of young men (aged 25 to 35 years) who may have not benefited from scale-up of HIV programming in the province. These older men need to be accessed and targeted with HIV sensitive social protection programmes. 
Table 2 Weighted HIV prevalence with unweighted counts, unadjusted ORs and 95\% Cls for sexually active men aged 15 to 24 years and 25 to 35 years in greater Edendale and Vulindlela areas, KwaZulu-Natal, South Africa (2014 to 2015)

\begin{tabular}{|c|c|c|c|c|c|}
\hline \multicolumn{3}{|l|}{ Young me } & \multicolumn{3}{|c|}{ Emerging adult men 25 to 35 years old } \\
\hline $\begin{array}{l}\text { HIV } \\
\text { prevalence }\end{array}$ & $\begin{array}{l}\text { Unweighted } \\
\mathrm{n} / \mathrm{N}\end{array}$ & $\begin{array}{l}\text { Unadjusted OR } \\
(95 \% \mathrm{Cl})\end{array}$ & $\begin{array}{l}\text { HIV } \\
\text { prevalence }\end{array}$ & $\begin{array}{l}\text { Unweighted } \\
\mathrm{n} / \mathrm{N}\end{array}$ & $\begin{array}{l}\text { Unadjuste } \\
(95 \% \mathrm{Cl})\end{array}$ \\
\hline
\end{tabular}

Socio-demographic factors

Relationship status

\begin{tabular}{|c|c|c|c|c|c|c|}
\hline Married & $\mathrm{n} / \mathrm{a}$ & $\mathrm{n} / \mathrm{a}$ & $\mathrm{n} / \mathrm{a}$ & 27.9 & $9 / 21$ & 0.7 (0.2 to 2.2$)$ \\
\hline Single, currently cohabiting & $\mathrm{n} / \mathrm{a}$ & $\mathrm{n} / \mathrm{a}$ & $\mathrm{n} / \mathrm{a}$ & 51.3 & $37 / 70$ & $1.8(1.0$ to 3.3$)$ \\
\hline Single, never cohabited & 7.9 & $83 / 916$ & 1.0 & 36.5 & $360 / 952$ & 1.0 \\
\hline \multicolumn{7}{|l|}{ Highest education } \\
\hline Incomplete schooling & 9.2 & $49 / 409$ & 1.3 (0.7 to 2.3$)$ & 46.3 & $221 / 471$ & 2.2 (1.5 to 3.0$)$ \\
\hline $\begin{array}{l}\text { Completed secondary } \\
\text { schooling }\end{array}$ & 7.2 & $36 / 524$ & 1.0 & 28.6 & $185 / 573$ & 1.0 \\
\hline \multicolumn{7}{|l|}{ Household Wealth } \\
\hline Poorest quintile & 10.2 & $15 / 147$ & 1.0 & 44.6 & $102 / 228$ & 1.0 \\
\hline Second quintile & 10.2 & $18 / 176$ & 0.8 (0.3 to 2.2 ) & 35.8 & $94 / 240$ & $0.7(0.5$ to 1.1$)$ \\
\hline Third quintile & 10.3 & $21 / 203$ & 0.8 (0.3 to 1.9$)$ & 34.4 & $78 / 201$ & 0.7 (0.4 to 1.0$)$ \\
\hline Fourth quintile & 8.3 & $16 / 193$ & 0.5 (0.2 to 1.3$)$ & 35.8 & $65 / 186$ & $0.7(0.4$ to 1.1$)$ \\
\hline Wealthiest quintile & 7.0 & $15 / 214$ & 0.5 (0.2 to 1.2$)$ & 37.4 & $67 / 188$ & $0.7(0.5$ to 1.1$)$ \\
\hline \multicolumn{7}{|c|}{ Household members receives social support grant } \\
\hline Yes & 8.5 & $42 / 451$ & $1.1(0.7$ to 2.0$)$ & 38.8 & $155 / 419$ & $0.9(0.6$ to 1.3$)$ \\
\hline No & 7.6 & $43 / 483$ & 1.0 & 35.9 & $251 / 625$ & 1.0 \\
\hline \multicolumn{7}{|l|}{ Food security } \\
\hline Food insecure & 9.4 & $19 / 181$ & 1.0 & 48.2 & 99/202 & 1.0 \\
\hline Food secure & 7.7 & $66 / 753$ & $0.8(0.4$ to 1.6$)$ & 33.9 & $307 / 842$ & $0.6(0.4$ to 0.8$)$ \\
\hline \multicolumn{7}{|c|}{ Been away from home more than 1 month in previous 12 months } \\
\hline Yes & 6.0 & 6/95 & 0.7 (0.3 to 1.8$)$ & 44.7 & $53 / 129$ & $1.4(0.8$ to 2.3$)$ \\
\hline No & 8.4 & $79 / 835$ & 1.0 & 36.1 & $353 / 912$ & 1.0 \\
\hline \multicolumn{7}{|l|}{ Behavioural factors } \\
\hline \multicolumn{7}{|l|}{ Ever had sex* } \\
\hline Yes & 8.1 & $85 / 934$ & 1.0 & 37.1 & $406 / 1044$ & 1.0 \\
\hline No & 6.8 & $38 / 538$ & 0.8 (0.5 to 1.4$)$ & 14.7 & $19 / 94$ & $0.3(0.2$ to 0.6$)$ \\
\hline \multicolumn{7}{|c|}{ Lifetime number of sex partners } \\
\hline $0-2$ & 6.9 & $26 / 342$ & 1.0 & 36.3 & $82 / 238$ & 1.0 \\
\hline$>2$ & 9.0 & $59 / 592$ & $1.3(0.7$ to 2.5$)$ & 37.4 & $324 / 806$ & 1.1 (0.7 to 1.6$)$ \\
\hline \multicolumn{7}{|c|}{ Sex partners in the past 12 months } \\
\hline $0-1$ & 8.9 & $46 / 512$ & $1.3(0.6$ to 2.5$)$ & 35.6 & $248 / 614$ & $0.7(0.5$ to 1.0$)$ \\
\hline$>1$ & 7.3 & $25 / 272$ & 1.0 & 44.1 & $114 / 280$ & 1.0 \\
\hline \multicolumn{7}{|l|}{ Condom use at first sex } \\
\hline Yes & 7.4 & 23/332 & 0.8 (0.4 to 1.6$)$ & 24.3 & $37 / 142$ & $0.5(0.3$ to 0.9$)$ \\
\hline No & 8.8 & $56 / 562$ & 1.0 & 39.7 & $344 / 840$ & 1.0 \\
\hline Don't remember & 6.9 & $6 / 40$ & $0.8(0.3$ to 2.1$)$ & 32.5 & $25 / 62$ & $0.7(0.4$ to 1.4$)$ \\
\hline \multicolumn{7}{|c|}{ Condom use most recent partner } \\
\hline Inconsistent & 8.0 & $64 / 640$ & 1.0 & 38.3 & $334 / 855$ & 1.0 \\
\hline Consistent & 8.3 & $21 / 294$ & $1.0(0.6$ to 1.9$)$ & 32.3 & $72 / 189$ & $0.8(0.5$ to 1.2$)$ \\
\hline \multicolumn{7}{|c|}{ Condom use in previous 12 months } \\
\hline Inconsistent & 8.7 & $53 / 524$ & 1.0 & 39.6 & $291 / 715$ & 1.0 \\
\hline Consistent & 7.6 & $18 / 260$ & $0.9(0.4$ to 1.8$)$ & 33.9 & $71 / 179$ & $0.8(0.5$ to 1.2$)$ \\
\hline
\end{tabular}


Table 2 Continued

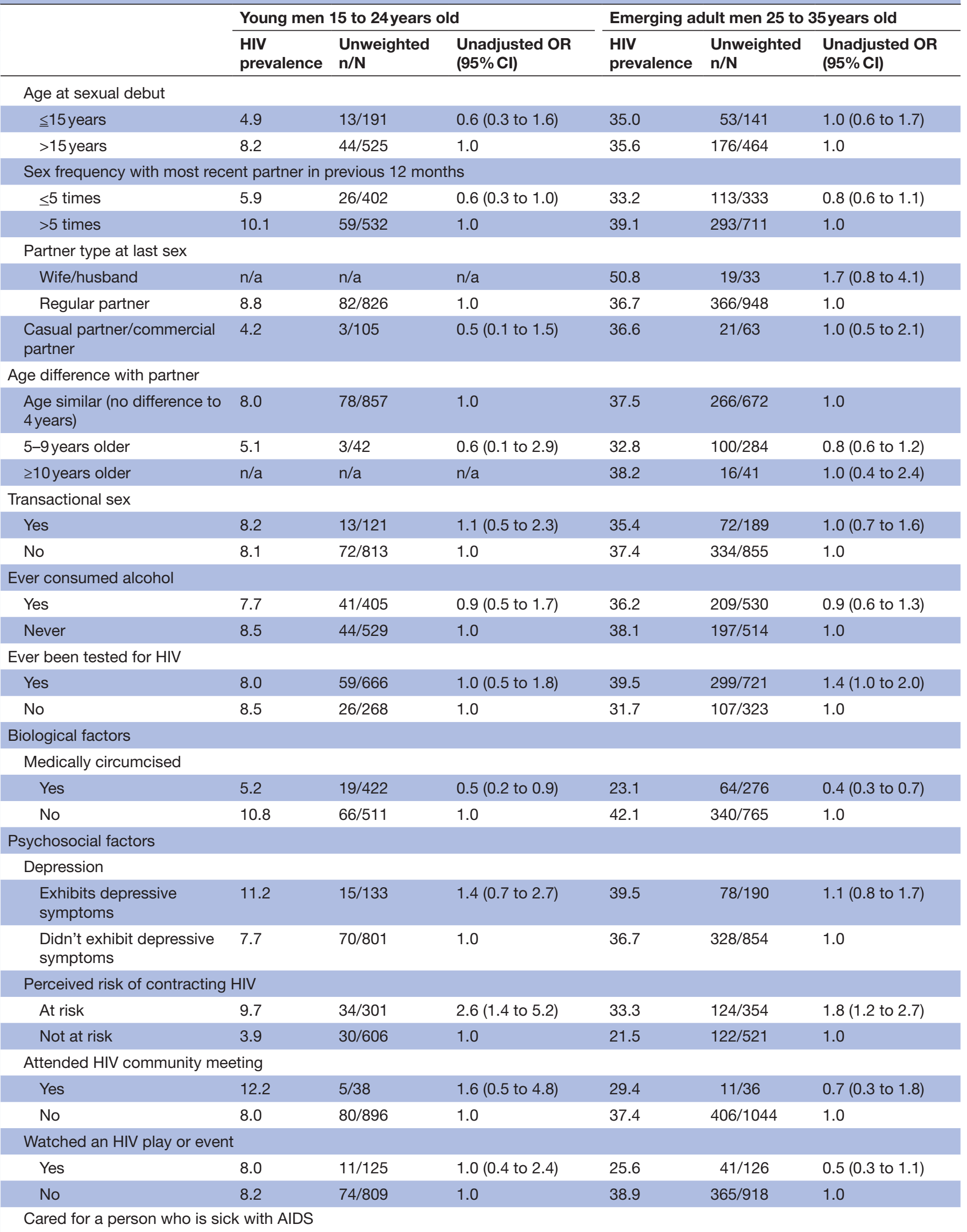




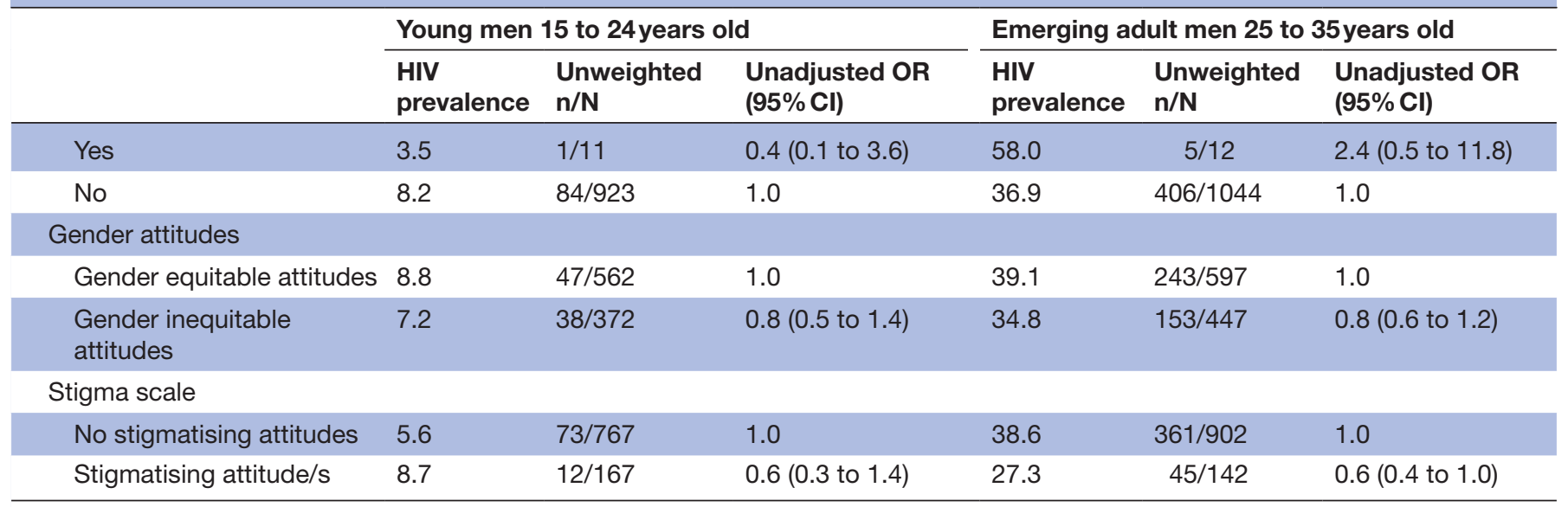

* indicates where sexually inactive men have been included as well. See online supplementary appendix 1 for more details on the items in each scale variable. If the OR is above 1 it means the category could be a risk factor for HIV. Where the n/a sign is used this category was excluded from the analysis as there were insufficient observations.

The results of this study should be interpreted with the study's limitations in mind. The cross-sectional nature of this study means that we are not able to establish the directionality between the economic, psychosocial and behavioural factors posited to influence HIV infection. Although the size of sample, location of the study and the type of psychosocial data collected means that this study provides important findings on which HIV prevention methods are likely to work in this area. Additionally, the self-reported nature of the sexual behaviour data means that there may be issues concerning reliability . To minimise this bias, fieldworkers were well trained to deal with sensitive topics. The data may still include men who are vertically infected with HIV, as some men can still be vertically infected and engage in sexual intercourse. The full sample of men only included 32 men who had sex with men, this was more than likely underreported . Therefore it is unlikely we can properly understand the HIV prevalence and HIV risk factors among this group of men. We omitted a number of variables in the regression analysis for younger men. This was done to minimise the likelihood of overfitting, we followed the 1 in 10 rule, that is, 1 predictor variable in the regression model for every 10 events. The younger men regression model had about 85 HIV events, hence we reduced the predictors to 14. Although we felt that theoretically it would not make sense to exclude too many of the variables and kept more than eight in the final model for younger men.

\section{CONCLUSIONS}

Overall, the findings indicate that eolder men are grappling with challenging social and material realities (food insecurity, incomplete education) while living with HIV in this community. Given that the epidemic is concentrated in the older male population, interventions need to find effective ways to get older men to undergo circumcision (and related health screening) and support HIV positive men to improve food security and household wealth. ${ }^{31}$ Younger men, while presenting with much lower HIV prevalence, than older men ${ }^{19} 20$ also face biological psychosocial change processes associated with transitioning from youth to adulthood that make them prone to engaging in sexual risk behaviours. ${ }^{32}{ }^{33} \mathrm{HIV}$ prevention programmes should target young men before sexual risk behaviours become entrenched. ${ }^{34}$

Acknowledgements Our sincere thanks to all household members and individual study participants who through their participation have contributed immensely to the understanding of the HIV epidemic in this region. A special thanks to the study staff for the field work, laboratory and Primary Health Care clinical staff in the district. We sincerely acknowledge all the HIPSS co-investigators from the following organisations: Epicentre, CAPRISA, HEARD, NICD and CDC. We thank our collaborating partners: The National Department of Health, Provincial KwaZulu-Natal Department of Health, uMgungundlovu Health District, the uMgungundlovu District AIDS Council, local, municipal and traditional leaders and community members for all their support throughout the HIPSS study.

Contributors $K G$ and SEB were responsible for the conception and design of the study, analysis and interpretation of the data and drafting of the article. KG, SEB, ABMK, LL, GG, FT, CC and DK participated in conception and design of the study, analysis and interpretation of the data and drafting the article. All authors read and approved the final article.

Funding This research has been supported by the President's Emergency Plan for AIDS Relief (PEPFAR) through the US Centers for Disease Control and Prevention (CDC) under the terms of operative agreement 3U2GGH000372-02W1. ABMK is supported by the joint South Africa-US Program for Collaborative Biomedical Research from the National Institutes of Health (R01HD083343).

Competing interests None declared.

Patient consent for publication Not required.

Ethics approval This study was approved by Biomedical Research Ethics Committee of the University of KwaZulu-Natal, (BF269/13), the US Centers for Disease Control and Prevention and the Department of Health, Province of KwaZuluNatal (HRKM 08/14).

Provenance and peer review Not commissioned; externally peer reviewed.

Data availability statement Data are available upon reasonable request.

Open access This is an open access article distributed in accordance with the Creative Commons Attribution Non Commercial (CC BY-NC 4.0) license, which permits others to distribute, remix, adapt, build upon this work non-commercially, and license their derivative works on different terms, provided the original work is 
Table 3 Weighted adjusted OR (AOR), p values and 95\% Cls for biological, psychosocial and socio-demographic factors associated with HIV positive status in sexually active men in two age groups in greater Edendale and Vulindlela areas, KwaZulu-Natal, South Africa (2014 to 2015)

\begin{tabular}{|c|c|c|c|c|}
\hline & \multicolumn{2}{|c|}{$\begin{array}{l}15-24 \\
\text { years old men }\end{array}$} & \multicolumn{2}{|c|}{$\begin{array}{l}25-35 \\
\text { years old men }\end{array}$} \\
\hline & AOR & AOR $95 \% \mathrm{Cl}$ & AOR & AOR $95 \% \mathrm{Cl}$ \\
\hline 20-24 years old (vs $15-19$ years old) & $2.45^{\star \star \star}$ & 1.18 to 5.08 & - & - \\
\hline 30-35 years old (vs 20-25 years old) & - & - & $2.36^{\star \star *}$ & 1.60 to 3.50 \\
\hline Married (vs never cohabited) & - & - & 0.57 & 0.16 to 2.03 \\
\hline Single but have cohabited (vs never cohabited) & - & - & 1.65 & 0.82 to 3.34 \\
\hline Completed secondary school (vs incomplete schooling) & 0.69 & 0.38 to 1.23 & $0.41^{\star \star *}$ & 0.27 to 0.63 \\
\hline Household wealth - second quintile (vs poorest quartile) & 0.76 & 0.25 to 2.32 & 0.58 & 0.31 to 1.08 \\
\hline Household wealth - third quintile (vs poorest quartile) & 0.78 & 0.28 to 2.18 & 0.68 & 0.39 to 1.20 \\
\hline Household wealth - fourth quintile (vs poorest quartile) & 0.55 & 0.19 to 1.60 & 0.89 & 0.48 to 1.66 \\
\hline Household wealth - wealthiest quintile (vs poorest quintile) & 0.50 & 0.15 to 1.63 & 1.01 & 0.56 to 1.82 \\
\hline $\begin{array}{l}\text { Receiving a social support grant in household (vs not receiving a } \\
\text { grant) }\end{array}$ & - & - & 0.71 & 0.49 to 1.03 \\
\hline Stayed at home (vs have been away from home) & 0.67 & 0.26 to 1.77 & 1.40 & 0.81 to 2.41 \\
\hline Number of lifetime sexual partners (per additional partner) $\dagger$ & 1.04 & 0.99 to 1.09 & 1.02 & 0.99 to 1.03 \\
\hline $\begin{array}{l}\text { Sex }>5 \text { times in past } 12 \text { months. (vs had sex }<5 \text { times in past } \\
12 \text { months.) }\end{array}$ & 1.58 & 0.88 to 2.85 & 1.15 & 0.77 to 1.72 \\
\hline $\begin{array}{l}\text { Consistent condom use for previous } 12 \text { months (vs inconsistent } \\
\text { use) }\end{array}$ & 1.05 & 0.51 to 2.16 & 0.85 & 0.52 to 1.38 \\
\hline Missing condom use data (vs inconsistent use) & 0.97 & 0.38 to 2.45 & 0.60 & 0.30 to 1.19 \\
\hline Younger than partner (vs not in age disparate partner) & - & - & $3.61^{*}$ & 1.25 to 10.45 \\
\hline 5 to 9 years older than partner (vs not in age disparate partner) & - & - & 0.63 & 0.40 to 1.00 \\
\hline$\geq 10$ years older than partner (vs not in age disparate partner) & - & - & 0.57 & 0.23 to 1.41 \\
\hline $\begin{array}{l}\text { Engaged in transactional sex (vs didn't engage in transactional } \\
\text { sex) }\end{array}$ & - & - & 0.91 & 0.51 to 1.65 \\
\hline Medically circumcised (vs uncircumcised) & $0-52$ & 0.25 to 1.09 & $0.58^{*}$ & 0.35 to 0.97 \\
\hline Food insecurity in household (one unit increase in food insecurity) $\dagger$ & - & - & $1.57^{*}$ & 1.05 to 2.34 \\
\hline Depression (one unit increase in depression) $\dagger$ & 1.02 & 0.96 to 1.09 & 0.99 & 0.94 to 1.04 \\
\hline Have drank alcohol (vs never consumed alcohol) & 0.77 & 0.38 to 1.56 & 0.70 & 0.46 to 1.08 \\
\hline n (unweighted) & 816 & & 861 & \\
\hline Pseudo $\mathrm{R}^{2}$ & 0.09 & & 0.19 & \\
\hline
\end{tabular}

Outcome variable is HIV status ( $0=$ HIV negative, $1=$ HIV positive). Only those who said they had ever had sex were included in the sample. Some variables were removed from the younger men model to make sure the model is not overfitted. A number of observations are missing (young men: $n=113$, older men: $n=174$ ) in the lifetime sexual partners variable because respondents refused to respond to this item. ${ }^{* *} \mathrm{p}<0.05^{* \star} \mathrm{p}<0.01{ }^{* \star \star} \mathrm{p}<0.001$

†See online supplementary appendix 1 for more details on the items in each scale variable.

properly cited, appropriate credit is given, any changes made indicated, and the use is non-commercial. See: http://creativecommons.org/licenses/by-nc/4.0/.

\section{ORCID iD}

Sean Edward Beckett http://orcid.org/0000-0002-6207-3454

\section{REFERENCES}

1 Joint United Nations Programme on HIV/AIDS. UNAIDS AIDSinfo, 2019. Available: https://aidsinfo.unaids.org/ [Accessed 26 Sept 2019].

2 Shand T, Thomson-de Boor $\mathrm{H}$, van den Berg W, et al. The HIV blind spot: men and HIV testing, treatment and care in sub-Saharan Africa. IDS Bull 2014;45:53-60.
3 Bor J, Rosen S, Chimbindi N, et al. Mass HIV treatment and sex disparities in life expectancy: demographic surveillance in rural South Africa. PLoS Med 2015;12:e1001905.

4 Sharma M, Barnabas RV, Celum C. Community-based strategies to strengthen men's engagement in the HIV care cascade in subSaharan Africa. PLoS Med 2017;14:e1002262.

5 Mills EJ, Beyrer C, Birungi J, et al. Engaging men in prevention and care for HIV/AIDS in Africa. PLoS Med 2012;9:e1001167.

6 Human Sciences Research Council. The fifth South African national HIV prevalence, incidence, behaviour and communication survey, 2017: HIV impact assessment summary report. Cape Town, 2018.

7 Rehle T, Johnson L, Hallett T, et al. A comparison of South African national HIV incidence estimates: a critical appraisal of different methods. PLoS One 2015;10:e0133255. 
8 Shisana O, Rehle T, Simbayi LC, et al. South African national HIV prevalence, incidence and behaviour survey 2012. Cape Town: HSRC Press, 2014.

9 Tanser F, Bärnighausen T, Grapsa E, et al. High coverage of art associated with decline in risk of HIV acquisition in rural KwaZuluNatal, South Africa. Science 2013;339:966-71.

10 Jewkes R, Dunkle K, Nduna M, et al. Factors associated with HIV sero-positivity in young, rural South African men. Int J Epidemiol 2006;35:1455-60.

11 Mah TL, Halperin DT. Concurrent sexual partnerships and the HIV epidemics in Africa: evidence to move forward. AIDS Behav 2010;14:11-16.

12 Leclerc-Madlala S. Age-disparate and intergenerational sex in southern Africa: the dynamics of hypervulnerability. AIDS 2008:22(Suppl 4):S17-25.

13 Shai NJ, Jewkes R, Nduna M, et al. Masculinities and condom use patterns among young rural South Africa men: a cross-sectional baseline survey. BMC Public Health 2012;12:462.

14 Simbayi LC, Kalichman SC, Jooste S, et al. Alcohol use and sexual risks for HIV infection among men and women receiving sexually transmitted infection clinic services in Cape town, South Africa. $J$ Stud Alcohol 2004;65:434-42.

15 Kalichman SC, Simbayi LC, Kaufman M, et al. Alcohol use and sexual risks for HIV/AIDS in sub-Saharan Africa: systematic review of empirical findings. Prev Sci 2007;8:141-51.

16 Ott MQ, Bärnighausen T, Tanser F, et al. Age-gaps in sexual partnerships: seeing beyond 'sugar daddies'. AIDS 2011;25:861-3.

17 Maughan-Brown B, Evans M, George G. Sexual behaviour of men and women within age-disparate partnerships in South Africa: implications for young women's HIV risk. PLoS One 2016;11:e0159162.

18 George G, Maughan-Brown B, Beckett S, et al. An Examination of Men's Wealth and Age Disparate Partnerships in South Africa: A Nationally Representative Cross-Sectional Survey. Sex Cult 2019;23:45-56.

19 Kharsany ABM, Cawood C, Khanyile D, et al. Strengthening HIV surveillance in the antiretroviral therapy era: rationale and design of a longitudinal study to monitor HIV prevalence and incidence in the uMgungundlovu district, KwaZulu-Natal, South Africa. BMC Public Health 2015;15:1149.

20 Kharsany ABM, Cawood C, Khanyile D, et al. Community-Based HIV prevalence in KwaZulu-Natal, South Africa: results of a crosssectional household survey. Lancet HIV 2018;5:e427-37.

21 Radloff LS. The CES-D scale: a self-report depression scale for research in the general population. Appl Psychol Meas 1977;1:385-401.
22 IBM. IBM SPSS Statistics for Windows [program]. 23 version. Armonk: NY: IBM Corp.

23 Pettifor AE, Rees HV, Kleinschmidt I, et al. Young people's sexual health in South Africa: HIV prevalence and sexual behaviors from a nationally representative household survey. AIDS 2005;19:1525-34

24 Grobler A, Cawood C, Khanyile D, et al. Progress of UNAIDS 90-9090 targets in a district in KwaZulu-Natal, South Africa, with high HIV burden, in the HIPSS study: a household-based complex multilevel community survey. The Lancet HIV 2017;4:e505-13.

25 Rehle T, Shisana O, Pillay V, et al. National HIV incidence measuresnew insights into the South African epidemic. S Afr Med J 2007;97:194-9.

26 UNESCO, UNFPA, UNAIDS. Fulfilling our promise to young people today 2013-2015 progress review: the eastern and southern African Ministerial commitment on comprehensive sexuality education and sexual and reproductive health services for adolescents and young people. Durban, 2016.

27 Bärnighausen T, Hosegood V, Timaeus IM, et al. The socioeconomic determinants of HIV incidence: evidence from a longitudinal, population-based study in rural South Africa. AIDS 2007:21:S29-38

28 Statistics South Africa. Statistics by place: local municipality, 2011. Available: http://www.statssa.gov.za/?page id=993\&id=themsunduzi-municipality [Accessed 26 Sept 2019].

29 Johnson S, Kincaid L, Figueroa M, et al. The third national HIV communication survey, 2012. Pretoria: JHHESA, 2013.

30 Njeuhmeli E, Hatzold K, Gold E, et al. Lessons learned from scale-up of voluntary medical male circumcision focusing on adolescents: benefits, challenges, and potential opportunities for linkages with adolescent HIV, sexual, and reproductive health services. J Acquir Immune Defic Syndr 2014;66:S193-9.

31 Suthar AB, Ford N, Bachanas PJ, et al. Towards universal voluntary HIV testing and counselling: a systematic review and meta-analysis of community-based approaches. PLoS Med 2013;10:e1001496.

32 Anderson KG, Beutel AM, Maughan-Brown B. HIV risk perceptions and first sexual intercourse among youth in Cape town South Africa. Int Fam Plan Perspect 2007;33:98-105.

33 Nduna M, Jewkes RK, Dunkle KL, et al. Associations between depressive symptoms, sexual behaviour and relationship characteristics: a prospective cohort study of young women and men in the eastern Cape, South Africa. J Int AIDS Soc 2010;13:44.

34 Govender K. The cool, the bad, the ugly, and the powerful: identity struggles in schoolboy peer culture. Cult Health Sex 2011;13:887-901. 